\title{
PERANCANGAN ALAT BANTU KERJA DENGAN PRINSIP ERGONOMI PADA BAGIAN PENIMBANGAN DI PT. BPI
}

\author{
Yuri Delano Regent Montororing ${ }^{1}$, Samuel Sihombing ${ }^{2}$ \\ ${ }^{1}$ Teknik Industri/ Fakultas Teknik/ Universitas Bhayangkara Jakarta Raya/ \\ yuri.delano@dsn.ubharajaya.ac.id \\ ${ }^{2}$ Teknik Industri/ Fakultas Teknik/ Universitas Bhayangkara Jakarta Raya/ \\ samuel.sihombing@gmail.com
}

\begin{abstract}
PT. BPI is a manufacturing company which produces plastic products. In the production process, manual material handling is required, namely weighing the plastic pellets to be fed into the injection machine. This process raises work complaints by employees, namely fatigue and illness in certain areas of the body. In order to reduce work fatigue, it is proposed to design an ergonomic weighing unit employee work aids using ergonomic principles with anthropometry. The previous condition was that the weighing process of raw materials was carried out by the staff of the weighing division on a stage with a height of 0.5 meters with dimensions of $4 m \times 2.5 \mathrm{~m}$. The proposal for the design of the work aid for the weighing division of PT. BPI is by adding work aids, namely the Lift Table with a length of $155 \mathrm{~cm}$, a width of 74 $\mathrm{cm}$ and $a$ height of $84 \mathrm{~cm}$.
\end{abstract}

Keywords: Working Facilities, Ergonomics, Anthropometri

\begin{abstract}
ABSTRAK,
PT. BPI merupakan perusahaan yang bergerak dalam bidang manufaktur yang memproduksi produk-produk plastik. Didalam proses produksinya diperlukan penanganan material secara manual yaitu penimbangan biji-biji plastik untuk kemudian dimasukan ke dalam mesin injeksi. Proses ini menimbulkan keluhan kerja oleh pegawai yaitu kelehan dan sakit di area badan tertentu. Agar dapat mengurangi kelelahan kerja diusulkan perancangan alat bantu kerja pegawai bagian penimbangan yang ergonomis menggunakan prinsip ergonomi dengan antropometri. Kondisi sebelumnya proses penimbangan bahan baku yang dilakukan pegawai bagian penimbangan dilakukan diatas panggung dengan tinggi 0,5 meter dengan dimensi $4 \mathrm{~m} x$ $2,5 \mathrm{~m}$. Usulan rancangan alat bantu kerja pegawai bagian penimbangan PT. BPI adalah dengan menambahkan alat bantu kerja yaitu Lift Table dengan panjang $155 \mathrm{~cm}$, lebar $74 \mathrm{~cm}$, dan tinggi $84 \mathrm{~cm}$.
\end{abstract}

Kata kunci: Alat bantu Kerja, Ergonomi, Anthropometri

\section{PENDAHULUAN}

PT. BPI adalah sebuah perusahaan yang bergerak di bidang manufaktur untuk colorant masterbatch (pewarna plastik) dan additive masterbatch untuk berbagai jenis plastik (PP, PE, PC, ABS, dan lain-lain). PT. BPI mengolah bahan-bahan kimia menjadi bijih plastik dan menjadi salah satu pemasok bahan baku plastik untuk perusahaan-perusahaan produksi plastik.

Didalam proses produksinya saat ini, PT.BPI masih menggunakan penanganan material secara manual sehingga menimbulkan masalah-masalah didalam kerja salah satunya yaitu gerakan kerja yang menyulitkan pekerja sehingga pekerja melakukan pekerjaanya dengan sulit. Selain itu fasilitas fisik yang ada di perusahaan dirasakan tidak sesuai dan kurang membantu pekerjaan operator, padahal alat bantu kerja sangat dibutuhkan oleh pekerja untuk mengurangi msalahmasalah kelelahan kerja yang terjadi dengan demikian dapat membuat keuntungan yang cukup besar bagi penggunanya (Amalia dan Wahyu, 2018). Pekerjaan yang dilakukan buruh 
merupakan pekerjaan yang memiliki resiko besar terhadap cedera (Sari, 2020). Setiap tahun, ada hampir seribu kali lebih banyak kecelakaan kerja non-fatal dibandingkan kecelakaan kerja fatal. Kecelakaan non fatal diperkirakan dialami 374 juta pekerja setiap tahun, dan banyak dari kecelakaan ini memiliki konsekuensi yang serius terhadap kapasitas penghasilan para pekerja (Hämäläinen, dkk., 2017).

Bagian penimbangan merupakan bagian yang sangat penting dalam kelancaran kegiatan produksi di PT. BPI. Target produksi biji plastik harus terpenuhi setiap harinya agar kepercayaan konsumen tetap berpihak kepada perusahaan dan tidak berpindah kepada kompetitor lain. Para operator di bagian penimbangan dalam melakukan pekerjaannya, posisi kerja mereka tidak sesuai dengan prinsip-prinsip ergonomi yaitu terlalu membungkuk, jangkauan tangan yang tidak normal yaitu agak jauh saat mengambil matrial yang telah di siapkan di atas palet yang diletakkan di panggung kerja, dan lain-lain. Sehingga dari posisi kerja operator tersebut dapat mengakibatkan timbulnya berbagai permasalahan yaitu kelelahan dan rasa nyeri pada punggung akibat dari membungkuk yang dilakukan secara bolak - balik ketika sedang melakukan proses penimbangan bahan baku yang di tuang ke dalam kontainer/ wadah penimbangan yang mengakibatkan posisi postur tubuh yang tidak ergonomis tersebut, maka timbul rasa nyeri pada bahu punggung, lengan, kaki serta pinggang yang sangat terasa sakit yang dikarenakan ketidaksesuaian antara pekerja dan lingkungan kerjanya.

Tabel 1.1 Data Rekam Medis Klinik PT. BPI Karyawan di Bagian Penimbangan

\begin{tabular}{cccc}
\hline Bulan & \multicolumn{2}{c}{ Jumlah Pegawai } & Keluhan \\
\cline { 2 - 3 } & Yang sakit & Total & \\
\hline Agustus 2018 & 2 & 6 & Sakit pinggang, pegal-pegal \\
September 2018 & 2 & 6 & Sakit pinggang, sakit lengan, pegal-pegal \\
Oktober 2018 & 3 & 6 & $\begin{array}{c}\text { Sakit pinggang, sakit punggung, sakit lengan, } \\
\text { pegal-pegal }\end{array}$ \\
November 2018 & 3 & 6 & Sakit pinggang, pegal-pegal, demam, diare \\
Desember 2018 & 4 & 6 & Sakit pinggang, pegal-pegal, demam \\
Januari 2019 & 5 & 6 & Sakit pinggang, pegal-pegal, demam \\
Februari 2019 & 6 & 6 & $\begin{array}{c}\text { Sakit pinggang, pegal-pegal, sakit punggung } \\
\text { Maret 2019 }\end{array}$ \\
& 6 & 6 & Sakit pinggang, sakit punggung, sakit lengan, \\
pegal-pegal, demam
\end{tabular}

Proses penimbangan yang dilakukan bagian penimbangan, dimulai dari pengambilan bahan baku yang sudah disiapkan oleh operator bagian gudang. Ukuran setiap bahan baku yang telah disediakan bagian gudang cukup besar, dan hampir semua berat rata - rata bahan baku adalah $25 \mathrm{~kg} / \mathrm{sak}$ (kemasan). Bahan baku yang diambil untuk setiap pembuatan satu jenis produk white 1591-BL adalah 8 ton/hari yang memerlukan bahan baku yang terdiri dari Titanium pigment omyacarb sebanyak $3744 \mathrm{~kg}$, titanium pigment R-104 sebanyak $1072 \mathrm{~kg}$, titanium R-903 sebanyak $464 \mathrm{~kg}$, resin LLDPE powder sebanyak $1200 \mathrm{~kg}$, resin templas 124 sebanyak $1200 \mathrm{~kg}$ dan powder aditife sebanyak $336 \mathrm{~kg}$ semua item bahan baku tersebut di timbang dalam kontainer/ wadah penimbangan yang berkapasitas $500 \mathrm{~kg} /$ kontainer. Proses penuangan ke dalam kontainer/ wadah penimbangan bahan baku ini dilakukan secara manual tanpa bantuan alat bantu apapun.

Pada penelitian akan diusulkan penambahan rancangan alat bantu kerja untuk mengatasi permasalahan kerja yang terjadi sehingga dapat menunjang peningkatan kerja dari operatornya. Karena dengan kondisi kerja yang baik dan tingkat kelelahan yang bisa dikendalikan, manusia sebagai pekerja akan mencapai produktivitas yang tinggi. Berdasarkan uraian tersebut, maka penelitian ini menerapkan ergonomi terhadap rancangan alat bantu kerja 
pada stasiun kerja dengan antropometri orang Indonesia pada perusahaan, agar operator bisa bekerja dengan efektif, nyaman, aman, sehat dan efisien. Dengan adanya perbaikan sistem kerja ini, diharapkan dapat menghasilkan suatu sistem kerja yang lebih tepat untuk mendapatkan hasil yang lebih baik. Diharapkan sistem kerja yang ada pada perusahaan ini dapat mengurangi tingkat cedera dan kelelahan sehingga perusahaan diharapkan dapat berkembang dan menjadi lebih baik.

Penelitian ini dilakukan untuk merancang sebuah alat bantu kerja pegawai bagian penimbangan PT. BPI yang sesuai dengan prinsip ergonomis yaitu membuat rancangan alat bantu kerja pegawai bagian penimbangan PT. BPI secara ergonomis agar pekerja dapat bekerja dengan efisien, nyaman, aman, sehat dan efektif serta tidak mudah lelah.

\section{LANDASAN TEORI}

\subsection{Ergonomi}

Ergonomi berasal dari Bahasa Latin Ergon (kerja) dan Nomos (peraturan, hukum alam). Menurut Nurmianto (2008), ergonomi adalah suatu studi mengenai aspek-aspek manusia dalam lingkungan kerja yang ditinjau dari fisiologi, anatomi, psikologi, manajemen dan perancangan. Ergonomi berhubungan dengan optimasi, efisiensi, kesehatan, keselamatan dan kenyamanan individu di tempat kerja dan di rumah. Di dalam ergonomi dibutuhkan system dimana manusia berinteraksi dengan fasilitas kerja dan lingkungannya.

Menurut Sulianta (2010), ergonomi adalah hubungan antara manusia dengan liengkungan kerjanya, yaitu keseluruhan alat perkakas dan bahan yang dihadapi, organisasi atau metode kerjanya dan lingkungan kerja sekitar. Harrington \& Gill (2005) mendefinisikan bahwa ergonomi merupakan ilmu dan pengaturan situasi kerja demi keuntungan pekerja dan majikan. Ilmu ini berupaya untuk menyerasikan mesin dengan pekerja, tidak menanggap bahea pekerja harus menyesuaikan diri dengan mesin dan lingkungan.

Berdasarkan definisi di atas, dapat disimpulkan bahwa ergonomic merupakan penerapan ilmu multidisiplin yang mempelajari interaksi antara manusia dalam hal ini adalah kemampuan dan kapasitasnya, alat kerja dan lingkungan kejra agar tercipta efisiensi dan produktivitas kerja yang maksimal (Harrington \& Gill, 2005)

\subsection{Tujuan Ergonomi}

Ergonomic bertujuan untuk menyediakan lingkungan yang memuaskan bagi pekerja untuk dapat melaksanakan tugas yang dituntutnya tanpa mengalami gangguan fisik dan mental. Analisis ergonomi terhadap memiliki manfaat untuk mengetahui apakah pekerjaan ini masih dalam kategori aman ditinjau dari keluhan yang dialami pekerja serta penilaian aspek ergonomi yang dilakukan (Sari, 2020).

Menurut Tarwaka (2008), tujuan dalam penerapan ergonomic, antara lain:

1. Meningkatkan kesejahteraan fisik dan mental melalui upaya pencegahan cidera dan penyakit akibat kerja, menurunkan beban kerja fisik dan mental, mengupayakan promosi dan kepuasan kerja.

2. Meningkatkan kesejahteraan sosial melalui peningkatan kualitas kontak sosial dan mengkoordinasi kerja secara tepat, guna meningkatkan jaminan sosial baik selama kurun waktu usia produktif maupun setelah tidak produktif.

3. Menciptakan keseimbangan rasional antara aspek teknis, ekonomis, dan antropologis dari setiap sistem kerja yang dilakukan sehingga tercipta kualitas kerja dan kualitas hidup yang tinggi. 


\subsection{Antropometri}

Menurut Wignjosoebroto (2009), antropometri berasal dari "anthro" yang berarti manusia dan "metri" yang berarti ukuran. Penerapan data ini adalah untuk penanganan masalah desain maupun ruang kerja. Hal-hal yang berhubungan dengan dimensi tubuh manusia seperti keadaan, frekuensi dan kesulitan, sikap badan, syarat-syarat untuk memudahkan bergerak.

Manusia pada umumnya mempunyai perbedaan bentuk dan ukuran tubuh. Terdapat beberapa faktor yang mempengaruhi bentuk dan ukuran tubuh manusia antara lain:

a. Umur

Secara umum dimensi tubuh manusia akan tumbuh dan bertambah besar seiring dengan bertambahnya umur yaitu sejak awal kelahirannya sampai dengan umur sekitar 20 tahun keatas.

b. Jenis Kelamin

Dimensi ukuran tubuh laki-laki umumnya akan lebih besar dibandingkan dengan wanita, terkecuali untuk beberapa bagian tubuh tertentu seperti pinggul, dan sebagainya.

c. Suku/Bangsa Setiap suku, bangsa ataupun kelompok etnik akan memiliki karakteristik fisik yang akan berbeda satu dengan yang lainnya.

d. Posisi Tubuh

Sikap (postur) ataupun posisi tubuh akan berpengaruh terhadap ukuran tubuh oleh sebab itu, posisi tubuh standar harus diterapkan untuk survei pengukuran (Haslindah, 2007).

Data antropometri yang menyajikan data ukuran dari berbagai macam anggota tubuh manusia dalam persentil tertentu akan sangat besar manfaatnya pada saat suatu rancangan produk ataupun alat bantu kerja akan dibuat. Agar rancangan suatu produk nantinya bisa sesuai dengan ukuran tubuh manusia yang akan mengoperasikannya, maka prinsip-prinsip apa yang harus diambil didalam aplikasi data antropometri tersebut harus ditetapkan terlebih dahulu seperti berikut ini:

a. Prinsip perancangan produk dengan ukuran yang ekstrim

b. Prinsip perancangan produk diantara rentang ukuran tertentu.

c. Prinsip perancangan produk dengan ukuran rata-rata.

Persentil adalah suatu nilai yang menyatakan persentase tertentu dari sekelompok orang yang memiliki dimensi tubuh yang ukurannya sama atau lebih kecil dari nilai tesebut. (Nurmianto, 2004).

\section{METODOLOGI PENELITIAN}

Penelitian ini menggunakan metode antropometri didalam perancangan alat bantu kerja berupa lifting table yang bisa disesuaikan tingginya. Langkah-langkah penelitian ini digambarkan sebagai berikut: 


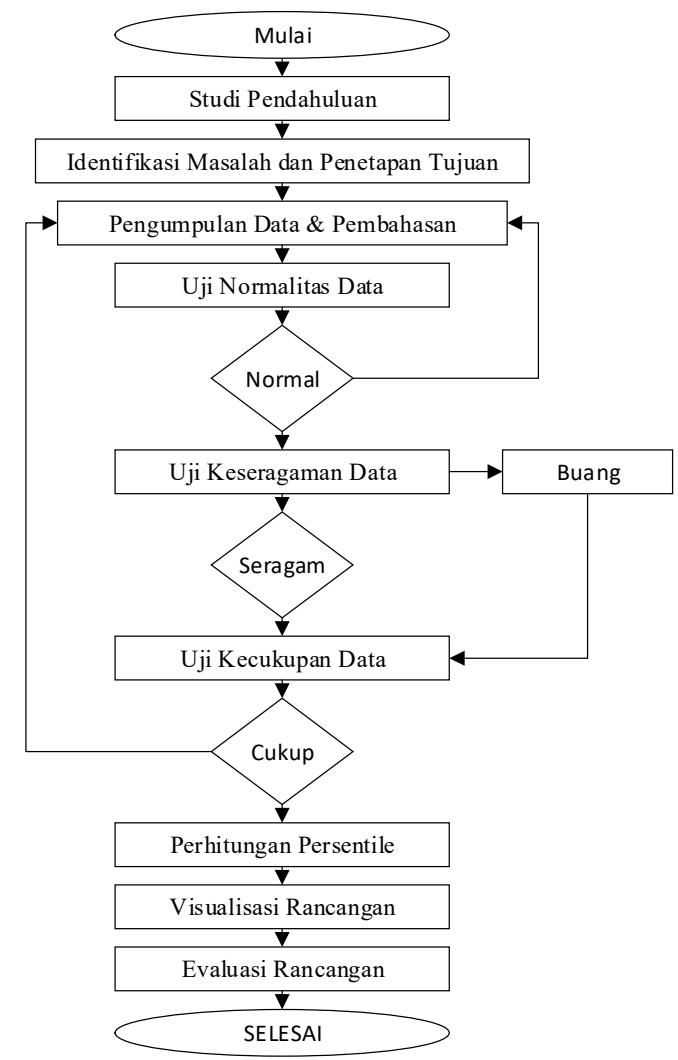

Gambar 1. Kerangka Pikir Penelitian

\section{PEMBAHASAN}

Tahapan langkah perancangan dan pengembangan produk dapat digunakan baik produk yang rumit maupun sederhana (Laurence dkk, 2018) dan berhasil dalam merancang dan mengembangkan berbagai jenis produk seperti meja ramah lingkungan (Hartono dkk, 2018).

Untuk penelitian ini data yang dikumpulkan terdiri dari data kegiatan penimbangan dan data antropometri pekerja. Data kegiatan penimbangan digunakan untuk menganalisa metode kerja dan data antropometri digunakan untuk merancang perbaikan alat bantu kerja.

\subsection{Data Antropometri Pekerja}

Data antropometri merupakan data hasil pengukuran ukuran dimensi bagian tubuh para pekerja. Dalam perancangan alat bantu kerja diperlukan data antropometri yang digunakan untuk menetapkan ukuran rancangan Lift Table. Hal ini dimaksudkan agar rancangan yang dihasilkan dapat digunakan dengan baik dan disesuaikan atau paling tidak mendekati karakteristik penggunanya.

Pengambilan data diperoleh dari hasil pengukuran antropometri pekerja pada bagian penimbangan PT. BPI sebanyak 6 orang. Adapun pengukuran data dimensi antropometri tersebut meliputi Tinggi Siku Berdiri (TSB), Lebar Bahu (LB), Diameter Lingkar Genggam (DLG), Lebar Jari ke-2,3,4,5 (LJ), Jangkauan Tangan ke Depan (JT) 
Tabel 1. Pengukuran Dimensi Tubuh

\begin{tabular}{|c|c|c|}
\hline $\begin{array}{l}\text { Data yang } \\
\text { Diukur }\end{array}$ & Cara Pengukuran & Kegunaan \\
\hline $\begin{array}{l}\text { Lebar Bahu } \\
\text { (LB) }\end{array}$ & $\begin{array}{l}\text { Subjek duduk tegak, ukur jarak } \\
\text { terluar antara bahu kanan dan } \\
\text { bahu kiri }\end{array}$ & $\begin{array}{l}\text { Untuk menentukan ukuran lebar } \\
\text { pegangan Lift Table }\end{array}$ \\
\hline Diameter & Ukur garis tengah lingkaran & Untuk menentukan diameter \\
\hline Lingkar & karena bertemunya ibu jari & pegangan Lift Table yang \\
\hline $\begin{array}{l}\text { Genggam } \\
\text { (DLG) }\end{array}$ & $\begin{array}{l}\text { dengan ujung telunjuk dan } \\
\text { dirasakan paling nyaman }\end{array}$ & digunakan \\
\hline Tinggi Siku & Ukur jarak vertikal antara siku & Untuk menentukan ukuran \\
\hline Berdiri (TSB) & dengan lantai pada posisi berdiri & $\begin{array}{l}\text { tinggi pegangan Lift Table dari } \\
\text { permukaan lantai }\end{array}$ \\
\hline Lebar Jari (LJ) & $\begin{array}{l}\text { Ukur jarak antara kelingking } \\
\text { bagian terluar dengan jari } \\
\text { telunjuk bagian terluar }\end{array}$ & $\begin{array}{l}\text { Untuk menentukan panjang } \\
\text { pegangan Lift Table }\end{array}$ \\
\hline $\begin{array}{l}\text { Jangkauan } \\
\text { Tangan (JT) }\end{array}$ & $\begin{array}{l}\text { Ukur jarak horisontal dari } \\
\text { punggung sampai ujung jari } \\
\text { tengah. Subjek berdiri tegak, }\end{array}$ & $\begin{array}{l}\text { Untuk menentukan jarak antara } \\
\text { operator dengan pegangan Lift } \\
\text { Table }\end{array}$ \\
\hline & $\begin{array}{l}\text { tangan direntangkan horizontal ke } \\
\text { depan }\end{array}$ & \\
\hline Rentangan & Ukur jarak horizontal dari ujung & Untuk menentukan panjang lift \\
\hline Tangan (RT) & $\begin{array}{l}\text { jari tengah kanan sampai ujung } \\
\text { jari tengah kiri ketika tangan di } \\
\text { rentangkan }\end{array}$ & \\
\hline
\end{tabular}

Data antropometri dapat dilihat pada Tabel 2. Data antropometri yang telah diukur kemudian dianalisis dengan melakukan perhitungan uji normalitas, uji keseragaman data, dan uji kecukupan data.

Tabel 2. Data Antropometri Pekerja Bagian Penimbangan

\begin{tabular}{lllllll}
\hline No & LB & TSB & DLG & LJ & JT & RT \\
\hline 1 & 36.3 & 91.4 & 3.4 & 5.2 & 77.7 & 158.5 \\
2 & 37.6 & 85.8 & 3.2 & 5.5 & 77.3 & 157.7 \\
3 & 34.4 & 85.5 & 3.6 & 5.3 & 82.9 & 158.4 \\
4 & 35.0 & 91.3 & 3.5 & 5.1 & 76.5 & 156.5 \\
5 & 34.5 & 86.4 & 3.3 & 5.2 & 76.9 & 155.2 \\
6 & 34.9 & 88.0 & 3.4 & 5.2 & 77.8 & 159.2 \\
\hline
\end{tabular}

\subsection{Pengujian Statistik}

4.2.1 Pengujian Normalitas

Untuk menguji kenormalan data antropometri, digunakan bantuan software SPSS Statistics. Uji statistik yang digunakan untuk uji normalitas data dalam penelitian ini adalah uji KolmogorovSmirnov. Hasil analisis ini kemudian dibandingkan dengan nilai kritisnya. Menurut Santoso (2007:154), menjelaskan output test of normality, adapun pedoman pengambilan keputusan, yaitu:

1. Angka signifikansi ( $\mathrm{Sig})>\alpha=0,05$ maka data berdistribusi normal

2. Angka signifikansi (Sig) $<\alpha=0,05$ maka data tidak berdistribusi normal 
Berdasarkan hasil uji normalitas yang telah dilakukan, dapat disimpulkan bahwa data untuk semua dimensi antropometri dalam penelitian ini terdistribusi normal, karena nilai tingkat signifikansi untuk semua dimensi lebih besar dari 0,05, yang dirangkum pata tabel berikut.

Tabel 3. Hasil Uji Normalitas Data Antropometri

\begin{tabular}{llll}
\hline Dimensi & Nilai Signifikansi & Nilai Kritis & Ket \\
\hline LB & 0.624 & 0.05 & Normal \\
TSB & 0.902 & 0.05 & Normal \\
DLG & 0.996 & 0.05 & Normal \\
LJ & 0.619 & 0.05 & Normal \\
JT & 0.298 & 0.05 & Normal \\
RT & 0.956 & 0.05 & Normal \\
\hline
\end{tabular}

\subsubsection{Pengujian Keseragaman Data}

Uji keseragaman data dilakukan untuk mengetahui apakah data yang telah diperoleh seragam atau tidak. Untuk keseragaman data diperoleh dengan melakukan perhitungan Batas Kontrol Atas (BKA) dan Batas Kontrol Bawah (BKB) untuk masing-masing dimensi data antropometri yang dihitung pada tingkat kepercayaan 95\%. Nilai BKA dan BKB bisa dihitung dengan rumus berikut ini:

$$
\mathrm{BKA} / \mathrm{BKB}=X \pm 2 \sigma
$$

Uji keseragaman data untuk semua dimensi antropometri dituliskan sebagai berikut.

Tabel 4. Hasil Uji Keseragaman Data Antrpometri

\begin{tabular}{lllll}
\hline No. & Dimensi & Rata-rata & BKA & BKB \\
\hline 1 & LB & 35.45 & 37.96 & 32.94 \\
2 & TSB & 88.07 & 93.44 & 82.69 \\
3 & DLG & 3.40 & 3.68 & 3.12 \\
4 & LJ & 5.25 & 5.53 & 4.97 \\
5 & JT & 78.18 & 82.91 & 73.46 \\
\hline
\end{tabular}

\subsubsection{Uji Kecukupan Data}

Uji kecukupan data dilakukan bertujuan untuk mengetahui apakah data yang diperoleh telah cukup atau tidak.

Tabel 5. Hasil Uji Kecukupan Data

\begin{tabular}{lllll}
\hline No. & Dimensi & N' & N & Ket. \\
\hline 1 & LB & 1.77 & 6 & Cukup \\
2 & TSB & 2.2 & 6 & Cukup \\
3 & DLG & 0.31 & 6 & Cukup \\
4 & LG & 0.12 & 6 & Cukup \\
5 & JT & 4.5 & 6 & Cukup \\
6 & RT & 1.76 & 6 & Cukup \\
\hline
\end{tabular}

\subsection{Perhitungan Persentil}

Perhitungan persentil yang dilakukan menggunakan persentil 5, persentil 50 dan persentil 95. Persentil 5 dimaksudkan agar ukuran persentil yang kecil dapat digunakan untuk ukuran orang besar dari data. Perhitungan Persentil 95 dimaksudkan agar ukuran persentil yang besar dapat digunakan untuk ukuran orang yang kecil dari data. Sedangkan Persentil 50 digunakan untuk sebuah rancangan yang tidak mensyaratkan kondisi orang besar dan orang kecil, karena dianggap tidak memiliki masalah jika ukuran yang diambil adalah rata-rata. 
Tabel 6. Hasil Perhitungan Persentil

\begin{tabular}{lllll}
\hline No & Dimensi & P5 & P50 & P95 \\
\hline 1 & LB & 33.39 & 35.45 & 38.36 \\
2 & TSB & 83.65 & 88.07 & 95.82 \\
3 & DLG & 3.17 & 3.40 & 3.63 \\
4 & LJ & 5.02 & 5.25 & 5.43 \\
5 & JT & 74.29 & 78.18 & 81.58 \\
6 & RT & 155.14 & 157.58 & 160.94 \\
\hline
\end{tabular}

\subsection{Perancangan Alat Bantu Kerja}

Pada tahap perancangan alat bantu kerja akan dilakukan penentuan spesifikasi rancangan yang terdiri dari:

1. Perhitungan Dimensi

Perhitungan dimensi dilakukan untuk menentukan ukuran rancangan yang akan dibuat. Perhitungan dimensi ini mengacu pada hasil perhitungan persentil yang telah dilakukan sebelumnya.

Tabel 7. Rekapitulasi Hasil Perhitungan Dimensi Lift Table

\begin{tabular}{lll}
\hline No. & Bagian & Ukuran \\
\hline 1 & Lebar Pegangan Lift Table & $58 \mathrm{~cm}$ \\
2 & Diameter Pegangan Lift Table & $4 \mathrm{~cm}$ \\
3 & Ketinggian Lift Table & $84 \mathrm{~cm}$ \\
4 & Panjang Lift Table & $155 \mathrm{~cm}$ \\
5 & Lebar Lift Table & $74 \mathrm{~cm}$ \\
\hline
\end{tabular}

2. Penentuan Komponen

Penentuan komponen penyusun pada usulan perancangan lift table bertujuan untuk menetapkan komponen yang akan digunakan sesuai dengan spesifikasi yang dibutuhkan. Penentuan komponen tersebut, meliputi:

a. Rangka

Rangka dijadikan sebagai kekuatan utama penopang keseluruhan beban, sehingga diperlukan bahan yang benar-benar kuat untuk menopang keseluruhan beban. Rangka tersebut terbuat dari material pipa besi stall dengan ukuran $25 \mathrm{~mm} \times 25$ $\mathrm{mm} \times 1,4 \mathrm{~mm}$. Material pipa besi stall dibuat dari bahan ST 37 yang memiliki massa jenis $7,86 \mathrm{~g} / \mathrm{cm}^{2}$. Penentuan ini mempertimbangkan bahwa baja ST 37 adalah material baja yang memiliki kontruksi yang kuat tetapi tetap ringan serta mudah didapat dipasaran tanpa harus melakukan pemesanan pada pabrik baja. Selain itu baja ST 37 merupakan jenis baja karbon menengah yang mudah dikerjakan dengan mesin dan mudah di las. 


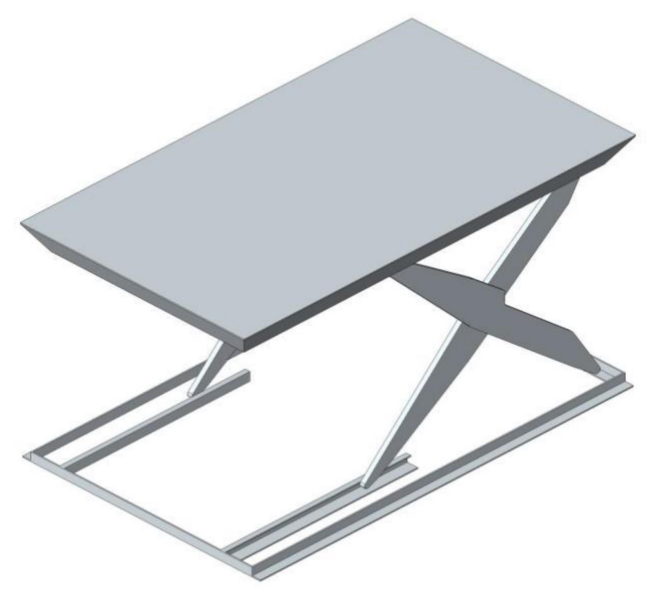

Gambar 2. Rangka Lift Table

b. Plat landasan lift table

Adapun bahan yang digunakan adalah plat baja karbon $0,2 \%$ (rol panas) dengan kekuatan luluh maksimal $=250 \mathrm{MPa}$. Adapun ukuran ketebalan plat baja adalah 5 $\mathrm{cm}$. Material tersebut dipilih karena memiliki konstruksi yang kuat tetapi tetap ringan, mudah dikerjakan dengan mesin dan mudah dilas. Selain itu, material baja tersebut mudah didapat di pasaran tanpa harus melakukan pemesanan pada pabrik baja. Sehingga diharapkan menjadi tumpuan kekuatan penopang landasan pada lift table yang dapat mengangkut beban dengan kapasitas sebesar $500 \mathrm{~kg}$.

c. Jenis Roda

Pemberian roda bertujuan untuk memudahkan pergerakan dan perpindahan dari alat bantu kerja yang berupa lift table dan dapat digunakan untuk mengimbangi gaya gesek kondisi permukaan jalan. Sedangkan fungsi dari pengunci roda dapat dijadikan memberikan kestabilan pada saat aktivitas loading dan unloading. Jenis roda dan penggunaan pengunci perlu direncanakan agar dapat mendukung $500 \mathrm{~kg}$. Roda yang digunakan dalam perancangan tersebut menggunakan 4 roda berbahan karet. Roda depan Berjumlah satu pasang (2 roda) tipe RKH berdiameter $10 \mathrm{~cm}$ dilengkapi kunci rumah, pengunci roda dan pelat baja dilas dan dilindungi oleh mur pengunci, nipel gemuk, poros roda terdapat mur. Spesifikasi roda depan bisa digerakkan (dinamis). Roda belakang berjumlah satu pasang ( 2 roda) tipe $\mathrm{RKH}$ berdiameter $10 \mathrm{~cm}$ dilengkapi kunci rumah, pengunci roda dan pelat baja di las dan dilindungi oleh mur pengunci, nipel gemuk, poros roda terdapat mur. Spesifikasi roda belakang tidak bisa digerakkan (tetap).

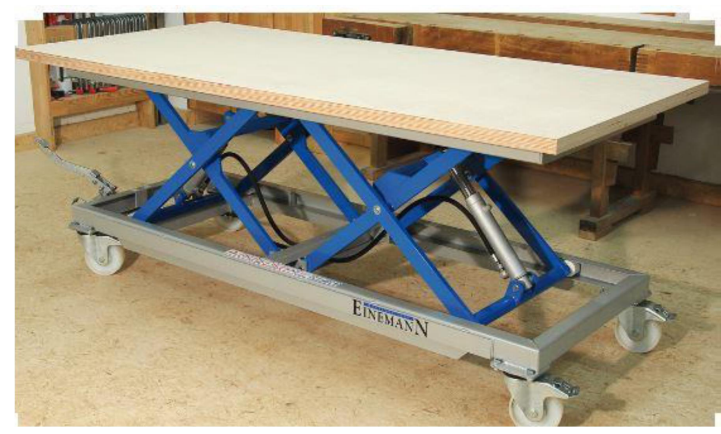

Gambar 3. Hasil Rancangan 


\section{KESIMPULAN DAN SARAN}

\subsection{Kesimpulan}

Berdasarkan hasil pembahasan, maka kesimpulan dalam penelitian ini adalah sebagai berikut:

1. Proses penimbangan bahan baku yang dilakukan pegawai Bagian Penimbangan dilkaukan diatas panggung dengan tinggi 0,5 meter dengan luar kira-kira $\mathrm{P} \times \mathrm{L}=4 \mathrm{~m} \times 2,5 \mathrm{~m}$. Permasalahan yang muncul ketika melakukan penimbangan bahan baku pada bagian penimbangan adalah ketika mulai menimbang dan di tuang kedalam kontainer/wadah penimbagan. Gerakan membungkuk, mengangkat, dan berjalan medekati wadah penimbangan dilakukan secara bolak balik secara terus menerus. Schedule kerja yang harus dilakukan oleh operator/pegawai bagian penimbangan dalam 1 shift kerja sebanyak 8 ton. Sehingga diperlukan sebuah alat bantu yang dapat memudahkan pegawai ketika mengangkat dengan berat $1 \mathrm{sak}=25 \mathrm{~kg}$ dan di timbang sebanyak $500 \mathrm{~kg}$ dalam 1 kontainer.

2. Keluhan kesehatan Cara mengatasi keluhan kesehatan pegawai Bagian Penimbangan dilakukan dengan dua cara, yaitu memperbaiki metode pengangkatan dan peletakan bahan baku (beban) dan menambahkan alat bantu kerja yang ergonomis.

3. Sebelum diusulkan sebuah alat bantu kerja, proses penimbangan dilakukan dengan mengangkat setiap bahan baku yang akan ditimbang secara bolak balik. Setelah usulan, ditambahkan sebuah alat bantu kerja berupa lift table yang diharapkan dapat membantu mempermudah proses penimbangan bahan baku. Alat bantu kerja yang diusulkan bersifat ergonomis sehingga dapat mengurangi atau bahkan menghilangkan keluhan ganggunan kesehatan akibat pekerjaan yang dilakukan. Rancangan alat bantu kerja adalah dengan menambahkan alat kerja yaitu Lift Table. Ukuran rancangan Lift Table yang diperlukan dengan panjang $155 \mathrm{~cm}$, lebar $74 \mathrm{~cm}$, dan tinggi $84 \mathrm{~cm}$

\subsection{Saran}

Saran yang dapat diberikan dari hasil penelitian ini sebagai bahan pertimbangan bagi perusahaan antara lain:

1. Usulan alat bantu kerja (lift table) yang diberikan hendaknya dilakukan uji kelayakan dan bahan yang akan digunakan untuk merancang alat bantu Lift Table adalah bahan yang berkualitas dan kuat dengan standart yang cukup, sehingga tidak memberikan dampak buruk terhadap proses penimbangan.

2. Pekerja (operator) harus melakukan kegiatan kerja dengan ergonomis agar rancangan alat bantu kerja dapat digunakan secara optimal sehingga hasil penimbangan dapat dilakukan dengan lebih akurat.

3. Dibuatkan standart operational prosedur (SOP) pada alat bantu kerja yang dibuat.

\section{DAFTAR PUSTAKA}

Amalia T, Wicaksana A.B. 2020. Identifikasi Potensi Bahaya Di Laboratorium Formulasi Pt $X$. Jurnal Inkofar. Volume 1 No 1 Juli.

Chuan T. K., Markus H., Naresh K. 2010. Anthropometry of the Singaporean and Indonesian populations. International Journal of Industrial Ergonomics. Volume 40, Issue 6, Pages $757-766$

Harrington J.M., Gill F.S.2003. Buku Saku Kesehatan Kerja. EGC. Jakarta

Haslindah. 2007. Analisa Ergonomi dala Perancangan Fasilitas Kerja untuk Proses Perontok Padi (Thresher) dengan Pendekatan Biomekanika. Jurnal Ilmu Teknik. Vol II, Nomor 3. 
Hämäläinen P., Takala J., Boon Kiat T., 2017. Perkiraan Global Kecelakaan Kerja dan Penyakit yang Berhubungan dengan Kerja, Kongres Dunia XXI tentang Keselamatan dan Kesehatan di Tempat Kerja. Singapura: Lembaga Keselamatan dan Kesehatan Kerja.

Laurence., Hartono N., Setiawan C. A. 2018. Prototype Design of Chicken Meat Cutting Tool. MATEC Web of Conference 218, EDP Sciences.

Montororing. Y.D.R. 2018. Usulan Penentuan Waktu Baku Proses Racking Produk Amplimesh Dengan Metode Jam Henti Pada Departemen Powder Coating. Jurnal Teknik FT UMT. Vol 7. No 2.

Nurmianto E. 2008. Ergonomi: Konsep Dasar dan Aplikasinya, Edisi Kedua. Surabaya: Guna Widya

Ramli S. 2010. Sistem Manajemen Keselamatan \& Kesehatan Kerja. OHSAS 18001. Jakarta : Dian Rakyat

Sari M.H.R.S.R. 2020. Penilaian Aspek Ergonomi Terhadap Buruh Angkut Arang. Jurnal Inkofar. Volume 1 No 1 Juli.

Sulianta. 2013. IT Ergonomics. Elex Media Komputindo

Tarwaka. 2008. Keselamatan dan Kesehatan Kerja. Surakarta : Harapan Press.

Sutalaksana I.Z. 2006. Teknik Perancangan Sistem Kerja. Institut Teknologi Bandung, Bandung Wignjosoebroto S. 2003. Teknik Tata Cara dan Pengukuran Kerja. Guna Widya, Surabaya. .

Wignjosoebroto S. 2009. Ergonomi Studi Gerak dan Waktu, Edisi Pertama. Jakarta: Guna Widya. 